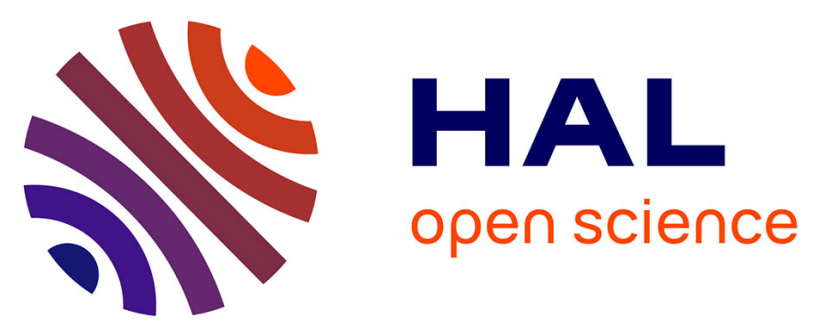

\title{
The need to improve detection and treatment of physical pain of Homeless people with Schizophrenia and Bipolar Disorders. Results from the French Housing First study
} Guillaume Fond, A. Tinland, M. Boucekine, V. Girard, S. Loubière, L. Boyer, P. Auquier

\section{- To cite this version:}

Guillaume Fond, A. Tinland, M. Boucekine, V. Girard, S. Loubière, et al.. The need to improve detection and treatment of physical pain of Homeless people with Schizophrenia and Bipolar Disorders. Results from the French Housing First study. Progress in Neuro-Psychopharmacology and Biological Psychiatry, 2019, 88, pp.175-180. 10.1016/j.pnpbp.2018.07.021 . hal-02473634

\section{HAL Id: hal-02473634 \\ https://hal-amu.archives-ouvertes.fr/hal-02473634}

Submitted on 10 Feb 2020

HAL is a multi-disciplinary open access archive for the deposit and dissemination of scientific research documents, whether they are published or not. The documents may come from teaching and research institutions in France or abroad, or from public or private research centers.
L'archive ouverte pluridisciplinaire HAL, est destinée au dépôt et à la diffusion de documents scientifiques de niveau recherche, publiés ou non, émanant des établissements d'enseignement et de recherche français ou étrangers, des laboratoires publics ou privés.

\section{(1) (1) $\$$}

Distributed under a Creative Commons Attribution - NonCommercial - NoDerivatives 44.0 
The need to improve detection and treatment of physical pain of Homeless people with Schizophrenia and Bipolar Disorders. Results from the French Housing First study.

Fond $\mathrm{G}^{1 *}$, Tinland $\mathrm{A}^{1,2}$, Boucekine $\mathrm{M}^{1,3}$, Girard $\mathrm{V}^{1,2}$, Loubière $\mathrm{S}^{1,3}$, Boyer $\mathrm{L}^{1}$, Auquier $\mathrm{P}^{1}$, French Housing First Study Group

'Aix Marseille Univ, School of medicine - La Timone Medical Campus, EA 3279 : CEReSS Health Service Research and Quality of life Center, Marseille, France

${ }^{2}$ Department of Psychiatry, Sainte-Marguerite University Hospital, Marseille, France.

${ }^{3}$ Assistance Publique Hôpitaux de Marseille, Service Epidémiologie et Economie de la Santé, Marseille, France

French Housing First Study Group:

T. Apostolidis, P. Birmes, T. Bosetti, R. Bouloudnine, B. Combes, J. Debieve, B. Falissard, T.

Greacen, C. Laval, C. Lancon, P. Le Cardinal, J. Mantovani, D. Moreau, J. Naudin, P. Rhunter, and B. Videau

Word counts: abstract $=208$; text body=3,337.

*Corresponding author:

Guillaume FOND, M.D., Ph.D.

Aix-Marseille Univ, EA 3279 - Public Health, Chronic Diseases and Quality of Life - Research

Unit

13284, Marseille, France

Tel.: +33-491384744; Fax: $\quad+33-491384482$

E-mail: guillaume.fond @ ap-hm.fr 


\section{Abstract}

Objective. The aim of this study was to investigate the prevalence and associated factors of physical pain in a large multicenter sample of Homeless Schizophrenia and Bipolar (HSB) patients.

Methods. This multicenter study was conducted in 4 French cities: Lille, Marseille, Paris and Toulouse. Pain was measured by EQ5D-3L questionnaire with no specified period or location. In addition, sociodemographic information, duration of homelessness, illness severity using the Modified Colorado Symptom Index (MCSI) and drug information were collected.

Results. Overall, 655 HSB patients, mean age 38.8 years and 82.6\% men were included, 448 (68.9\%) were diagnosed with schizophrenia and 202 (31.1\%) with bipolar disorder. More than half patients $(\mathrm{N}=337,51.5 \%)$ reported moderate to extreme physical pain while only $2.7 \%$ were administered analgesic drugs. In the multivariate analysis, self-reported moderate to extreme physical pain was associated with antidepressant consumption (adjusted odd ratio $\mathrm{aOR}=2.56[1.25 ; 5.26], \mathrm{p}=0.01)$, female gender $(\mathrm{aOR}=1.72[1.03 ; 2.86], \mathrm{p}=0.04)$, bipolar disorders (vs. schizophrenia) $(\mathrm{aOR}=1.81[1.19 ; 2.77], \mathrm{p}=0.006)$, older age $(\mathrm{aOR}=1.03$ [1.01;1.05], $\mathrm{p}=0.01)$, with higher MCSI psychotic score $(\mathrm{a} 0 \mathrm{R}=1.04[1.01 ; 1.06], \mathrm{p}=0.002)$, independently of the number of days in the street during the last 180 days, MCSI depression score, alcohol and substance use disorders, psychotropic drugs and analgesic treatments. No association with education level, antipsychotics, mood stabilizers, anxiolytic, hypnotic or medication adherence was found (all $\mathrm{p}>0.05)$.

Conclusion. Physical pain was highly reported in homeless patients with severe mental illness with insufficient care. Physical pain should be systematically explored and treated in this population. Bipolar disorders, antidepressant consumption and female gender may be targeted in priority. Age and psychotic symptomatology were found to influence self-reported pain in a marginal way.

Keywords. Schizophrenia; Bipolar Disorders, Homelessness; physical pain, EQ5D

\section{Introduction}

Schizophrenia (SZ) and Bipolar Disorders (BD) are over-represented in homeless 
populations compared to non-homeless populations. The management of Homeless Schizophrenia or Bipolar Disorders (HSB) patients is challenging because this sub-population of homeless people is among the most vulnerable and hardest to reach (Auquier et al., 2013).

SZ and BD patients are underdiagnosed and undertreated with high rates of physical comorbidities (Correll et al., 2017; Godin et al., 2015; Vancampfort et al., 2016a, 2015). SZ patients are twice more likely to report chronic pain in comparison to healthy controls (Birgenheir et al., 2013). It remains currently unknown how many SZ patients have pain issues (Brendon Stubbs et al., 2015b). In a recent French cross-sectional study, 22\% of SZ subjects reported moderate to high rates of physical pain (Fond et al., 2018). SZ individuals may have a higher pain threshold (for review see (Engels et al., 2014)). Mood disorders and especially bipolar disorders have been extensively associated with increased physical pain (B. Stubbs et al., 2015). Antidepressants and anxiolytics are both frequently prescribed in schizophrenia and bipolar disorders (Fond et al., 2017a) and have been associated with respectively pain relief (Gebhardt et al., 2016) and pain improvement in chronic medical conditions (Abdel Shaheed et al., 2017). In summary, while physical pain may deeply impact quality of life, adherence into treatment, depression, functioning and recovery, little is known about self-reported pain prevalence and management in SZ and BD housed people, and even less is known about that in the HSB.

The aim of this study was therefore to investigate the prevalence of self-reported physical pain and associated factors in a large multicenter sample of HSB subjects.

\section{Methodology}

Study design and population

The French Housing First program was a multicenter randomized controlled trial conducted in 4 large French cities: Lille, Marseille, Paris and Toulouse (Tinland et al., 2013). The inclusion criteria were as follows: age over 18 years; absolute homelessness (i.e., no fixed place to stay for at least the past 7 nights with little likelihood of finding a place in the upcoming month) or precarious housing situation (housed in single-room occupancy, rooming house, or hotel/motel as a primary residence AND a history of 2 or more episodes of being absolutely homeless in the past year OR one episode of being absolutely homeless for at least 4 weeks in the past year); diagnosis of SZ or BD by a psychiatrist based on the Diagnostic and Statistical 
Manual of Mental Disorders, 4th ed. (DSM-IV-TR) criteria (American Psychiatric Association, 2000); and the ability to speak French. Mobile mental health outreach teams recruited patients from August 2011 to April 2014 in the street, emergency shelters, hospitals and jails. Psychiatrists and research assistants performed the evaluations during face-to-face interviews in the offices of the mobile mental health outreach teams, which were located in the downtown area of each city. The current analysis comprised only baseline data ( $\mathrm{t} 0$, before any intervention) for HSB patients who have completed the EQ5D-3L questionnaire.

\section{Data collection}

The following data were collected:

- $\quad$ Pain measure (EQ5D-3L questionnaire). The EQ5D-3L is a patient-reported outcome measure including five dimensions: mobility, self-care, usual activities, pain/discomfort and anxiety/depression, and each dimension has three levels (no problem, some problems, extreme problem). This questionnaire was developed by the EuroQol Group, a network of international multidisciplinary researchers devoted to the measurement of health status (van Hout et al., 2012). The EQ5D has been validated in SZ individuals (König et al., 2007). The subjects were classified in the "pain group" if they reported moderate to extreme pain level (EQ-5D-3L pain score $\geq 2$ ) (Fond G., et al., 2018).

- Sociodemographic information: gender, age, education level, duration of lifetime homelessness, number of days in the street in the last 180 days.

- $\quad$ Illness characteristics: perceived mental health was assessed with the Modified Colorado Symptom Index (MCSI) (Conrad et al., 2001). The MCSI contains 14 items that address how often in the past month an individual has experienced a variety of mental health symptoms, including psychotic and depression subscores. Higher scores indicate a greater likelihood of mental health problems. Substance use was assessed with section L of the MINI (Sheehan et al., 1998), and alcohol consumption was evaluated with the Alcohol Use Disorders Identification Test (AUDIT) (Saunders et al., 1993).

- Drug information: drug class (antipsychotic, mood stabilizers, antidepressant, anxiolytic, analgesic, opioid substitute) and adherence assessed with the French version of the Medication Adherence Rating Scale (MARS) (Fond et al., 2017b; Zemmour et al., 2016) were reported. The 
MARS is a 10-item, multidimensional, self-reporting instrument that describes a global level of adherence (index). Higher scores indicate a higher likelihood of medication adherence.

\section{Statistical analysis}

All variables are presented using measures of means and dispersion (standard deviation) for continuous data and frequency distribution for categorical variables. The data were examined for normal distribution with the Shapiro-Wilk test and for homogeneity of variance with the Levene test. Univariate associations between demographic and clinical characteristics of patients with self-reported moderate to extreme pain were performed using the chi-square test for categorical variables. Continuous variables were analyzed with Student t-tests for normally distributed data and Mann-Whitney tests in case of non-normal distributions.

A multivariate logistic regression including age, gender, number of days in the street during the previous 180 days and all variables associated with self-reported pain in univariate analysis (with $\mathrm{p}<0.2$ ) was performed to estimate the adjusted Odds Ratio (aOR) and its corresponding 95\% confidence interval (CI) for an association between demographic and clinical characteristics of patients with moderate to extreme pain levels.

All of the tests were two-sided. Statistical significance was defined as $p<0.05$. Statistical analysis was performed using the SPSS version 20.0 software package (SPSS Inc., Chicago, IL, USA). This study was a confirmatory analysis. The hypothesis was that moderate to extreme pain levels were associated with higher psychotic and depressive symptoms levels, lower antidepressant and anxiolytic consumption, with higher addictive behaviors and with lower analgesic consumption. No correction for multiple testing has been therefore carried out, consistently with recommendations (Bender and Lange, 2001).

\section{Ethical approval}

The study was conducted in accordance with the principles of the Declaration of Helsinki, 6th revision. All participants provided written consent. The local ethics committee (Comité de Protection des Personnes Sud-Méditerranée V, France: trial number 11.050) and the French Drug and Device Regulation Agency (trial number 2011-A00668-33) approved the study. 


\section{Results}

In total, 655 HSB patients were included in this study. Their sociodemographic and clinical characteristics are presented in table 1 . The mean age of the sample was 38.8 years (standard deviation=10.0), and 82.6\% were men, 448 (68.9\%) were diagnosed with SZ and 202 (31.1\%) with bipolar disorders. More than half of patients $(\mathrm{N}=337,51.5 \%)$ reported moderate to extreme physical pain. Only $269(60 \%)$ of the SZ patients were administered antipsychotics, and $38(24.1 \%)$ of the BD patients were administered mood stabilizers.

The results of univariate and multivariate analyses are presented in table 1. Among patients treated by antidepressants, 39 (7.7\%) were treated with selective-serotonin reuptake inhibitors (SSRI) and 12 (1.8\%) with norepinephrine and serotonine reuptake inhibitors (NSRI). Overall, only $8(1.2 \%)$ patients were administered ladder 1 analgesic (paracetamol) and 8 patients ladder 2 or 3 analgesics and 2 patients had no drug class information. Four patients $(0.8 \%)$ were administered low-dose aspirin and $2(0.4 \%)$ corticoids; none of these antiinflammatory drugs was associated with lower rate of reported physical pain.

In the multivariate analysis, higher self-reported moderate to extreme physical pain has been associated with antidepressant consumption $(\mathrm{aOR}=2.56[1.25 ; 5.26], \mathrm{p}=0.01)$, female gender $(\mathrm{aOR}=1.72[1.03 ; 2.86], \mathrm{p}=0.04)$, bipolar disorders (vs. schizophrenia) $(\mathrm{aOR}=1.81[1.19 ; 2.77]$, $\mathrm{p}=0.006)$, older age $(\mathrm{aOR}=1.03$ [1.01;1.05], $\mathrm{p}=0.01)$, with higher MCSI psychotic score $(\mathrm{a} 0 \mathrm{R}=1.04[1.01 ; 1.06], \mathrm{p}=0.002)$, independently of the number of days in the street during the last 180 days, MCSI depression score, alcohol and substance use disorders, psychotropic drugs and analgesic treatments. No association with education level, number of lifetime psychiatric hospitalizations or medication adherence has been found (all $\mathrm{p}>0.05$ ).

\section{Discussion}

The major findings of the present study may be summarized as follows: in a large multicenter sample of HSB subjects, more than half reported moderate to extreme physical pain that has been associated with female gender, BD diagnosis, antidepressant consumption and more marginally with higher psychotic symptomatology and older age. No association with homelessness duration or other sociodemographic characteristics has been found.

Bipolar disorders have been associated with higher physical pain compared to schizophrenia in the present work $(63.9 \%$ vs. $45.8 \%)$. This is consistent with the literature 
suggesting that SZ patients may have decreased pain threshold (Stubbs et al., 2014) and that mood disorders may be associated with increased pain sensitivity (Köhler-Forsberg et al., 2017). In a meta-analysis including $171,000 \mathrm{BD}$ patients and more than 12 million controls, the prevalence of pain in BD patients was estimated to be $28.9 \%$ [16.4\%;43.4\%] (B. Stubbs et al., 2015). In another meta-analysis including 242,000 SZ subjects and more than 4 million controls, the prevalence of pain in schizophrenia has been found to be higher than in bipolar disorders (34.7\% [23.6\%-46.6\%] (Stubbs et al., 2014). In comparison with these results, the rates of selfreported pain are extremely high in our HSB patients. Bipolar disorders have been associated with fibromyalgia, a common and complex chronic pain disorder (Bortolato et al., 2016; Di Tommaso Morrison et al., 2017; Nicholl et al., 2014). Fibromyalgia has not been explored in the present study; this limit should be taken into account in future studies. Altogether, the present study suggests that physical pain is much frequently reported in homeless patients with severe mental illness than in their non-homeless counterparts, especially in bipolar disorders but also in schizophrenia. Only $2.7 \%$ of the patients were treated by analgesic medication. The absence of statistically significant association between analgesic treatment and self-reported pain is probably due to this low rate. This result is consistent with studies suggesting that patients with severe mental illness are less treated for physical complaint than other mentally healthy patients (Fond et al., 2018; Godin et al., 2015). The rate of $45.8 \%$ of self-reported moderate to extreme pain in SZ should also be compared to the rate of $22 \%$ of SZ French patients referred in the Schizophrenia Expert Centers (mean age 32 years, three quarters males) who reported moderate to extreme physical pain assessed with the same questionnaire (Fond et al., 2018). Self-reported pain is therefore almost 2 times higher in homeless SZ subjects compared to non-homeless one. Altogether, the present results suggest that physical pain is highly frequent and undertreated in homeless subjects with mental illness.

Women were found to report more frequently physical pain than men. This is consistent with previous studies carried out in mentally healthy populations suggesting that women were more prone to report physical pain than men, especially through catastrophizing (Keefe et al., 2000). Catastrophizing is defined as a set of exaggerated negative thoughts about actual or anticipated pain (Sullivan et al., 2001) and has not been assessed in the present study, which is a limit. 
Psychotic symptomology (as measured by the MCSI psychotic subscore) has been marginally associated with physical pain $(\mathrm{aOR}=1.04)$, which suggests that psychotic delusions do not explain increased self-reported pain in SZ patients. This result is not consistent with the literature suggesting increased pain threshold in SZ subjects (Stubbs et al., 2014). This is probably due to the fact that the EQ5D-3L explores chronic physical pain, while previous studies have focused on acute stimulated pain (like thermal pain). The mechanisms of acute vs. chronic pain are different.

Contrary to what could have been expected (Bernstein et al., 2016), no association between depression symptomatology and self-reported pain has been found in the present study. On the contrary, subjects who were administered antidepressants reported more frequently physical pain than those who were not, independently of depressive symptoms. This result is inconsistent with the results of a previous meta-analysis suggesting that antidepressant were effective in alleviating pain independently of the class of antidepressant (Gebhardt et al., 2016). This apparent paradox is probably due to the populations included. A meta-analysis of experimental studies suggests potential effects of depression on pain perception are variable and likely to depend upon multiple factors (Thompson et al., 2016). In the present study, only SZ and BD subjects have been included, while subjects with SZ and BD were excluded from the studies included in the Gebhardt's meta-analysis. Those conflicting results suggest that the relationship between antidepressant consumption and self-reported pain is complex, inconsistent across mental disorders and deserves further explorations to understand the mechanisms of antidepressants' pain relief. In our study, pain has not been associated with adherence to treatment, which suggests that the observed phenomenon is not due to a lack of adherence. Contrary to the findings of a previous study (Abdel Shaheed et al., 2017), anxiolytics have not been associated with decreased physical pain in our sample. This may be due to the long-term administration of anxiolytics, which may lead to the loss of effectiveness via an increase of tolerance (Gravielle, 2016). The length of each treatment administration has not been reported, which is a limit of the present work.

Our study has highlighted that only $60 \%$ of the SZ subjects and $24 \%$ of the BD subjects were administered appropriate treatment (respectively antipsychotics and mood stabilizers) while $48 \%$ of the subjects were administered long-term anxiolytics and $20 \%$ long-term hypnotics despite the risk of dependency. This suggests that a high proportion of HSB patients are not 
administered background regimens for their mental illness. This is probably due to patients' factors (Paudyal et al., 2017). Future studies should determine the factors associated with

adequate treatment in HSB patients to improve the rate of patients correctly treated. On the same way, $38.8 \%$ were diagnosed with alcohol use disorder and $45.4 \%$ with substance use disorder, which suggests high rates of comorbid addictive behavior. However, no association between alcohol use disorder and pain has been found, contrary to what could have been expected from analgesic effects of alcohol (Thompson et al., 2017). This discrepancy is probably due to the difference between acute and chronic alcohol consumption. Future studies should determine if these addictive behaviors are correctly diagnosed and treated. Finally, the very low rate of analgesic prescription $(2.7 \%)$ is consistent with a previous study that has suggested under analgesic prescription in subjects with psychotic disorders (around 1-2\%) (Brendon Stubbs et al., 2015a).

\section{Limitations and perspectives}

In addition to the above-mentioned limits, several interesting data points were not collected and should be included in future studies. History of childhood trauma has not been explored and may be associated with physical pain in subjects with mental illness (SachsEricsson et al., 2017). Metabolic syndrome may also be associated with pain and has not been explored (Vancampfort et al., 2016b). Chronic somatic illnesses have not been reported in the present study. The EQ5D-3L has not been specifically developed for pain report and therefore does not mention how long, where or what is causing pain. The sources of pain should be further explored. Back pain is a major cause of disability and could be explored in priority (Stubbs et al., 2016), as well as headache/migraine that have been highly reported in housed SZ subjects (Fond et al., 2018).

Strengths. While the present sample may not have been representative of the HSB patients, this study has the larger sample size compared to previous studies carried on similar populations ( $n=94$ (Maremmani et al., 2017), n=165 (Rezansoff et al., 2017)). Pain has been evaluated with a one-item auto-questionnaire, however it has been well validated in SZ individuals with good intrinsic and extrinsic properties (König et al., 2007). Somatic treatments, 
and especially analgesic treatments, were reported, which was not the case in previous study carried out in SZ patients referred to the Expert Centers (Fond et al., 2018).

Altogether, these results suggest that pain is highly prevalent and undertreated in HSB subjects. Non-pharmacological interventions should also be developed for pain management, like mindfulness, physical activity, diet and lifestyle modifications (Vancampfort et al., 2017). However these approaches are insufficiently provided to homeless subjects to date and should be developed in the future.

\section{Conclusion}

The present results have suggested that more than half HSB patients report moderate to extreme physical pain while less than $3 \%$ receive analgesic treatments. Bipolar disorders, female gender and antidepressant consumption (and older age and psychotic symptomatology in a marginal way) have been associated with increased self-reported physical pain, but SZ subjects reported also high rates of physical pain compared to other samples. Future longitudinal studies should determine effective strategies to improve physical pain in homeless patients with severe mental disorders, and should determine if improving physical pain may further improve mental outcomes and commitment into health care. 


\section{References}

Abdel Shaheed, C., Maher, C.G., Williams, K.A., McLachlan, A.J., 2017. Efficacy and tolerability of muscle relaxants for low back pain: Systematic review and meta-analysis. Eur. J. Pain Lond. Engl. 21, 228-237. https://doi.org/10.1002/ejp.907

American Psychiatric Association, 2000. APA (2000) Diagnostic and Statistical Manual of Mental Disorders, 4th ed. Text revised. American Psychiatric Association, Washington, DC. Auquier, P., Tinland, A., Fortanier, C., Loundou, A., Baumstarck, K., Lancon, C., Boyer, L., 2013. Toward Meeting the Needs of Homeless People with Schizophrenia: The Validity of Quality of Life Measurement. PLOS ONE 8, e79677. https://doi.org/10.1371/journal.pone.0079677

Bender, R., Lange, S., 2001. Adjusting for multiple testing-when and how? J. Clin. Epidemiol. 54, 343-349. https://doi.org/10.1016/S0895-4356(00)00314-0

Bernstein, E.E., Rabideau, D.J., Gigler, M.E., Nierenberg, A.A., Deckersbach, T., Sylvia, L.G., 2016. Patient perceptions of physical health and bipolar symptoms: The intersection of mental and physical health. J. Affect. Disord. 189, 203-206. https://doi.org/10.1016/j.jad.2015.09.052 Birgenheir, D.G., Ilgen, M.A., Bohnert, A.S.B., Abraham, K.M., Bowersox, N.W., Austin, K., Kilbourne, A.M., 2013. Pain conditions among veterans with schizophrenia or bipolar disorder. Gen. Hosp. Psychiatry 35, 480-484. https://doi.org/10.1016/j.genhosppsych.2013.03.019 Bortolato, B., Berk, M., Maes, M., McIntyre, R.S., Carvalho, A.F., 2016. Fibromyalgia and Bipolar Disorder: Emerging Epidemiological Associations and Shared Pathophysiology. Curr. Mol. Med. 16, 119-136.

Conrad, K.J., Yagelka, J.R., Matters, M.D., Rich, A.R., Williams, V., Buchanan, M., 2001. Reliability and validity of a modified Colorado Symptom Index in a national homeless sample. Ment. Health Serv. Res. 3, 141-153.

Correll, C.U., Solmi, M., Veronese, N., Bortolato, B., Rosson, S., Santonastaso, P., ThapaChhetri, N., Fornaro, M., Gallicchio, D., Collantoni, E., Pigato, G., Favaro, A., Monaco, F., Kohler, C., Vancampfort, D., Ward, P.B., Gaughran, F., Carvalho, A.F., Stubbs, B., 2017. Prevalence, incidence and mortality from cardiovascular disease in patients with pooled and specific severe mental illness: a large-scale meta-analysis of 3,211,768 patients and 113,383,368 controls. World Psychiatry Off. J. World Psychiatr. Assoc. WPA 16, 163-180. https://doi.org/10.1002/wps.20420

Di Tommaso Morrison, M.C., Carinci, F., Lessiani, G., Spinas, E., Kritas, S.K., Ronconi, G., Caraffa, A., Conti, P., 2017. Fibromyalgia and bipolar disorder: extent of comorbidity and therapeutic implications. J. Biol. Regul. Homeost. Agents 31, 17-20.

Engels, G., Francke, A.L., van Meijel, B., Douma, J.G., de Kam, H., Wesselink, W., Houtjes, W., Scherder, E.J.A., 2014. Clinical pain in schizophrenia: a systematic review. J. Pain Off. J. Am. Pain Soc. 15, 457-467. https://doi.org/10.1016/j.jpain.2013.11.005

Fond, G., Berna, F., Boyer, L., Godin, O., Brunel, L., Andrianarisoa, M., Aouizerate, B., Capdevielle, D., Chereau, I., Danion, J.M., Dubertret, C., Dubreucq, J., Faget, C., Gabayet, F., Le Gloahec, T., Llorca, P.M., Mallet, J., Misdrahi, D., Rey, R., Richieri, R., Passerieux, C., Portalier, C., Roux, P., Vehier, A., Yazbek, H., Schürhoff, F., Bulzacka, E., FACE-SZ (FondaMental Academic Centers of Expertise for Schizophrenia) group, 2017a. Benzodiazepine long-term administration is associated with impaired attention/working memory in schizophrenia: results from the national multicentre FACE-SZ data set. Eur. Arch. Psychiatry Clin. Neurosci. https://doi.org/10.1007/s00406-017-0787-9 
Fond, Guillaume, Boyer, L., Andrianarisoa, Meja, Godin, O., Bulzacka, Ewa, Berna, Fabrice, Brunel, Lore, Coulon, N., Aouizerate, Bruno, Capdevielle, Delphine, Chereau, I., D’amato, T., Denizot, Hélène, Dubertret, Caroline, Dubreucq, Julien, Faget, Catherine, Leignier, S., Mallet, Jasmina, Misdrahi, David, Rey, Romain, Lancon, C., Passerieux, Christine, Schandrin, Aurélie, Urbach, Mathieu, Vidailhet, Pierre, Leboyer, Marion, Schurhoff, Franck, Llorca, P.-M., FACESZ (FondaMental Academic Centers of Expertise for Schizophrenia) group, Andrianarisoa, M., Aouizerate, B., Berna, F., Blanc, O., Brunel, L., Bulzacka, E., Capdevielle, D., Chereau-Boudet, I., Chesnoy-Servanin, G., Jm, D., D’Amato, T., Deloge, A., Delorme, C., Denizot, H., Dorey, J.M., Dubertret, C., Dubreucq, J., Faget, C., Fluttaz, C., Fond, G., Fonteneau, S., Gabayet, F., Giraud-Baro, E., Honciuc, R.M., Lacelle, D., Lançon, C., Laouamri, H., Leboyer, M., Le Gloahec, T., Le Strat, Y., Llorca, null, Mallet, J., Metairie, E., Misdrahi, D., Offerlin-Meyer, I., Passerieux, C., Peri, P., Pires, S., Portalier, C., Rey, R., Roman, C., Sebilleau, M., Schandrin, A., Schurhoff, F., Tessier, A., Am, T., Urbach, M., Vaillant, F., Vehier, A., Vidailhet, P., Vilà, E., Yazbek, H., Zinetti-Bertschy, A., 2018. Self-reported pain in patients with schizophrenia. Results from the national first-step FACE-SZ cohort. Prog. Neuropsychopharmacol. Biol. Psychiatry. https://doi.org/10.1016/j.pnpbp.2018.04.007

Fond, G., Boyer, L., Boucekine, M., Aden, L.A., Schürhoff, F., Tessier, A., Andrianarisoa, M., Berna, F., Brunel, L., Capdevielle, D., Chereau, I., Mallet, J., Denizot, H., Dorey, J.M., Dubertret, C., Dubreucq, J., Faget, C., Gabayet, F., Rey, R., Richieri, R., Passerieux, C., Schandrin, A., Urbach, M., Vidailhet, P., Llorca, P.M., Misdrahi, D., FACE-SZ (FondaMental Academic Centers of Expertise for Schizophrenia) group, 2017b. Validation study of the Medication Adherence Rating Scale. Results from the FACE-SZ national dataset. Schizophr. Res. 182, 84-89. https://doi.org/10.1016/j.schres.2016.10.023

Fond G., et al., 2018. Insufficient remission of depression in subjects with schizophrenia and comorbid major depressive disorder. Results from the FACE-SZ cohort. Br. J. Psychiatry. Gebhardt, S., Heinzel-Gutenbrunner, M., König, U., 2016. Pain Relief in Depressive Disorders: A Meta-Analysis of the Effects of Antidepressants. J. Clin. Psychopharmacol. 36, 658-668. https://doi.org/10.1097/JCP.0000000000000604

Godin, O., Leboyer, M., Gaman, A., Aouizerate, B., Berna, F., Brunel, L., Capdevielle, D., Chereau, I., Dorey, J.M., Dubertret, C., Dubreucq, J., Faget, C., Gabayet, F., Le Strat, Y., Llorca, P.M., Misdrahi, D., Rey, R., Richieri, R., Passerieux, C., Schandrin, A., Schürhoff, F., Urbach, M., Vidalhet, P., Girerd, N., Fond, G., FACE-SZ group, 2015. Metabolic syndrome, abdominal obesity and hyperuricemia in schizophrenia: Results from the FACE-SZ cohort. Schizophr. Res. https://doi.org/10.1016/j.schres.2015.07.047

Gravielle, M.C., 2016. Activation-induced regulation of GABAA receptors: Is there a link with the molecular basis of benzodiazepine tolerance? Pharmacol. Res. 109, 92-100.

https://doi.org/10.1016/j.phrs.2015.12.030

Keefe, F.J., Lefebvre, J.C., Egert, J.R., Affleck, G., Sullivan, M.J., Caldwell, D.S., 2000. The relationship of gender to pain, pain behavior, and disability in osteoarthritis patients: the role of catastrophizing. Pain 87, 325-334.

Köhler-Forsberg, O., Sylvia, L., Thase, M., Calabrese, J.R., Deckersbach, T., Tohen, M., Bowden, C.L., McInnis, M., Kocsis, J.H., Friedman, E.S., Ketter, T.A., McElroy, S., Shelton, R.C., Nierenberg, A.A., 2017. Nonsteroidal anti-inflammatory drugs (NSAIDs) and paracetamol do not affect 6-month mood-stabilizing treatment outcome among 482 patients with bipolar disorder. Depress. Anxiety 34, 281-290. https://doi.org/10.1002/da.22601

König, H.-H., Roick, C., Angermeyer, M.C., 2007. Validity of the EQ-5D in assessing and 
valuing health status in patients with schizophrenic, schizotypal or delusional disorders. Eur. Psychiatry J. Assoc. Eur. Psychiatr. 22, 177-187. https://doi.org/10.1016/j.eurpsy.2006.08.004 Maremmani, A.G.I., Bacciardi, S., Gehring, N.D., Cambioli, L., Schütz, C., Jang, K., Krausz, M., 2017. Substance Use Among Homeless Individuals With Schizophrenia and Bipolar Disorder. J. Nerv. Ment. Dis. 205, 173-177. https://doi.org/10.1097/NMD.0000000000000462 Nicholl, B.I., Mackay, D., Cullen, B., Martin, D.J., Ul-Haq, Z., Mair, F.S., Evans, J., McIntosh, A.M., Gallagher, J., Roberts, B., Deary, I.J., Pell, J.P., Smith, D.J., 2014. Chronic multisite pain in major depression and bipolar disorder: cross-sectional study of 149,611 participants in UK Biobank. BMC Psychiatry 14, 350. https://doi.org/10.1186/s12888-014-0350-4

Paudyal, V., MacLure, K., Buchanan, C., Wilson, L., Macleod, J., Stewart, D., 2017. "When you are homeless, you are not thinking about your medication, but your food, shelter or heat for the night": behavioural determinants of homeless patients' adherence to prescribed medicines. Public Health 148, 1-8. https://doi.org/10.1016/j.puhe.2017.03.002 Rezansoff, S.N., Moniruzzaman, A., Fazel, S., McCandless, L., Procyshyn, R., Somers, J.M., 2017. Housing First Improves Adherence to Antipsychotic Medication Among Formerly Homeless Adults With Schizophrenia: Results of a Randomized Controlled Trial. Schizophr. Bull. 43, 852-861. https://doi.org/10.1093/schbul/sbw136 Sachs-Ericsson, N.J., Sheffler, J.L., Stanley, I.H., Piazza, J.R., Preacher, K.J., 2017. When Emotional Pain Becomes Physical: Adverse Childhood Experiences, Pain, and the Role of Mood and Anxiety Disorders. J. Clin. Psychol. 73, 1403-1428. https://doi.org/10.1002/jclp.22444 Saunders, J.B., Aasland, O.G., Babor, T.F., de la Fuente, J.R., Grant, M., 1993. Development of the Alcohol Use Disorders Identification Test (AUDIT): WHO Collaborative Project on Early Detection of Persons with Harmful Alcohol Consumption--II. Addict. Abingdon Engl. 88, 791804.

Sheehan, D.V., Lecrubier, Y., Sheehan, K.H., Amorim, P., Janavs, J., Weiller, E., Hergueta, T., Baker, R., Dunbar, G.C., 1998. The Mini-International Neuropsychiatric Interview (M.I.N.I.): the development and validation of a structured diagnostic psychiatric interview for DSM-IV and ICD-10. J. Clin. Psychiatry 59 Suppl 20, 22-33; quiz 34-57.

Stubbs, B., Eggermont, L., Mitchell, A.J., De Hert, M., Correll, C.U., Soundy, A., Rosenbaum, S., Vancampfort, D., 2015. The prevalence of pain in bipolar disorder: a systematic review and large-scale meta-analysis. Acta Psychiatr. Scand. 131, 75-88. https://doi.org/10.1111/acps.12325 Stubbs, Brendon, Gardner-Sood, P., Smith, S., Ismail, K., Greenwood, K., Patel, A., Farmer, R., Gaughran, F., 2015a. Pain is independently associated with reduced health related quality of life in people with psychosis. Psychiatry Res. 230, 585-591.

https://doi.org/10.1016/j.psychres.2015.10.008

Stubbs, B., Koyanagi, A., Thompson, T., Veronese, N., Carvalho, A.F., Solomi, M., Mugisha, J., Schofield, P., Cosco, T., Wilson, N., Vancampfort, D., 2016. The epidemiology of back pain and its relationship with depression, psychosis, anxiety, sleep disturbances, and stress sensitivity: Data from 43 low- and middle-income countries. Gen. Hosp. Psychiatry 43, 63-70. https://doi.org/10.1016/j.genhosppsych.2016.09.008

Stubbs, B., Mitchell, A.J., De Hert, M., Correll, C.U., Soundy, A., Stroobants, M., Vancampfort, D., 2014. The prevalence and moderators of clinical pain in people with schizophrenia: a systematic review and large scale meta-analysis. Schizophr. Res. 160, 1-8. https://doi.org/10.1016/j.schres.2014.10.017

Stubbs, Brendon, Thompson, T., Acaster, S., Vancampfort, D., Gaughran, F., Correll, C.U., 2015b. Decreased pain sensitivity among people with schizophrenia: a meta-analysis of 
experimental pain induction studies. Pain 156, 2121-2131.

https://doi.org/10.1097/j.pain.0000000000000304

Sullivan, M.J., Thorn, B., Haythornthwaite, J.A., Keefe, F., Martin, M., Bradley, L.A., Lefebvre, J.C., 2001. Theoretical perspectives on the relation between catastrophizing and pain. Clin. J.

Pain 17, 52-64.

Thompson, T., Correll, C.U., Gallop, K., Vancampfort, D., Stubbs, B., 2016. Is Pain Perception Altered in People With Depression? A Systematic Review and Meta-Analysis of Experimental Pain Research. J. Pain Off. J. Am. Pain Soc. 17, 1257-1272.

https://doi.org/10.1016/j.jpain.2016.08.007

Thompson, T., Oram, C., Correll, C.U., Tsermentseli, S., Stubbs, B., 2017. Analgesic Effects of Alcohol: A Systematic Review and Meta-Analysis of Controlled Experimental Studies in Healthy Participants. J. Pain Off. J. Am. Pain Soc. 18, 499-510.

https://doi.org/10.1016/j.jpain.2016.11.009

Tinland, A., Fortanier, C., Girard, V., Laval, C., Videau, B., Rhenter, P., Greacen, T., Falissard, B., Apostolidis, T., Lançon, C., Boyer, L., Auquier, P., 2013. Evaluation of the Housing First program in patients with severe mental disorders in France: study protocol for a randomized controlled trial. Trials 14, 309. https://doi.org/10.1186/1745-6215-14-309

van Hout, B., Janssen, M.F., Feng, Y.-S., Kohlmann, T., Busschbach, J., Golicki, D., Lloyd, A., Scalone, L., Kind, P., Pickard, A.S., 2012. Interim scoring for the EQ-5D-5L: mapping the EQ5D-5L to EQ-5D-3L value sets. Value Health J. Int. Soc. Pharmacoeconomics Outcomes Res. 15, 708-715. https://doi.org/10.1016/j.jval.2012.02.008

Vancampfort, D., Correll, C.U., Galling, B., Probst, M., De Hert, M., Ward, P.B., Rosenbaum, S., Gaughran, F., Lally, J., Stubbs, B., 2016a. Diabetes mellitus in people with schizophrenia, bipolar disorder and major depressive disorder: a systematic review and large scale metaanalysis. World Psychiatry Off. J. World Psychiatr. Assoc. WPA 15, 166-174.

https://doi.org/10.1002/wps.20309

Vancampfort, D., Firth, J., Schuch, F.B., Rosenbaum, S., Mugisha, J., Hallgren, M., Probst, M., Ward, P.B., Gaughran, F., De Hert, M., Carvalho, A.F., Stubbs, B., 2017. Sedentary behavior and physical activity levels in people with schizophrenia, bipolar disorder and major depressive disorder: a global systematic review and meta-analysis. World Psychiatry Off. J. World Psychiatr. Assoc. WPA 16, 308-315. https://doi.org/10.1002/wps.20458

Vancampfort, D., Sienaert, P., Wyckaert, S., De Hert, M., Stubbs, B., Kinyanda, E., Probst, M., 2016b. The Metabolic Syndrome Is Associated with Self-Reported Physical Complaints in Patients with Bipolar Disorder. Psychiatr. Danub. 28, 139-145.

Vancampfort, D., Stubbs, B., Mitchell, A.J., De Hert, M., Wampers, M., Ward, P.B., Rosenbaum, S., Correll, C.U., 2015. Risk of metabolic syndrome and its components in people with schizophrenia and related psychotic disorders, bipolar disorder and major depressive disorder: a systematic review and meta-analysis. World Psychiatry Off. J. World Psychiatr. Assoc. WPA 14, 339-347. https://doi.org/10.1002/wps.20252

Zemmour, K., Tinland, A., Boucekine, M., Girard, V., Loubière, S., Resseguier, N., Fond, G., Auquier, P., Boyer, L., French Housing First Study Group, 2016. Validation of the Medication Adherence Rating Scale in homeless patients with schizophrenia: Results from the French Housing First experience. Sci. Rep. 6, 31598. https://doi.org/10.1038/srep31598 